\title{
BIẾN ĐỔI NỒNG ĐỘ GLUCOSE MÁU Ở BÊNH NHÂN ĐỘT QUỴ NÃO \\ GIAI ĐOẠN CẤP TÍNH TRƯỚC VÀ SAU ĐIỀU TRI TẠI BỆNH VIỆN Nguyễn Văn Minh ${ }^{1}$, Phạm Quốc Toản ${ }^{2}$, Hoàng Trüng Vinh ${ }^{2}$ 1. Bệnh viện Trung Vuoong- TP. Hồ Chí Minh \\ 2. Học viện Quân y
}

DOI: $10.47122 / v j d e .2020 .38 .4$

\begin{abstract}
Changes in blood glucose level in patients with acute stroke before and after treatment in the hospital

Objectives: To assess changes in blood glucose level in patients with acute stroke before and after treatment in the hospital. Subjects and methods: 98 acute stroke patients treated with combined therapy including stroke treatment and use of insulin if having indication were evaluated variation in blood glucose level before and after treatment in the hospital. Results: After treatment, blood glucose level decreased in all participants including patients with or without stress hyperglycemia, diabetic or non-diabetic patients before stroke. Blood glucose level at the time of death of fatal patients was higher than that of non-fatal ones. Conclusions: Blood glucose level after treatment in stroke patients decreased significantly, did not depend on patients with or without stress hyperglycemia and diabetes mellitus before stroke.
\end{abstract}

Keywords: stroke; ischemic stroke; hemorrhagic stroke; diabetes mellitus; stress hyperglycemia;

\section{TÓM TẮT}

Mục tiêu: Đánh giá biến đổi nồng độ glucose máu ở bệnh nhân đột quỵ não (BN ĐQN) giai đoạn cấp tính trước và sau thời gian điều trị tại bệnh viện. Đối tương và phương pháp: $98 \mathrm{BN}$ ĐQN cấp tính được điều trị bằng các biện pháp phối hợp bao gồm điều trị ĐQN và sử dụng insulin nếu có chỉ định, được đánh giá biến đổi nồng độ glucose máu trước và sau thời gian điều trị tại bệnh viện. Kết quả: Nồng độ glucose máu giảm ở tất cả các đối tượng kể cả có hay không có tăng glucose máu phản ứng, ở $\mathrm{BN}$ đái tháo đường (ĐTĐ) hay không có ĐTĐ trước khi đột quy. Nồng độ glucose máu ở đối tượng tại thời điểm tử vong cao hơn so với đối tượng không tử vong. Kết luận: Nồng độ glucose máu ở $\mathrm{BN} Đ Q \mathrm{~N}$ sau thời gian điều trị tại bệnh viện giảm có ý nghĩa không phụ thuộc vào có hay không có tăng glucose máu phản ứng trước đó, ở cả $\mathrm{BN}$ ĐTĐ và không ĐTĐ.

Tù khóa: Đột quy. não, nhồi máu não, chảy máu não, đái tháo đường, tăng glucose máu phản ứng.

Chịu trách nhiệm chính: Hoàng Trung Vinh

Ngày nhận bài:9/01/2020

Ngày phản biện khoa học:12/01/2020

Ngày duyệt bài: 28/02/2020

Email: hoangvinh.hvqy@gmail.com

ĐT: 0903201250

\section{1. ĐẠT VẤN Đề}

Đột quỵ não là biến cố cấp tính, nguy hiểm đến tính mạng, tỷ lệ ngày càng gia tăng, là nguyên nhân gây tử vong đứng hàng thứ 2 sau nhồi máu cơ tim cấp tính. Trong giai đoạn cấp của bệnh, cơ thể xuất hiện nhiều biến đổi ở các cơ quan, tổ chức hoặc quá trình chuyển hóa trong đó có rối loạn chuyển hóa carbohydrat. Dù là BN ĐTĐ hay không ĐTĐ trước khi xảy ra ĐQN đều có thể xuất hiện biến đổi nồng độ glucose máu trong đó có tăng glucose máu phản ứng. Theo khuyến cáo thì ở $\mathrm{BN}$ ĐQN giai đoạn cấp nếu glucose $>$ $7,8 \mathrm{moml} / 1$ đều có chỉ định sử dụng insulin bởi vì trong glucose là yếu tố ảnh hưởng bất lợi đến tiến triển và tiên lượng bệnh. Đề tài nghiên cứu nhằm mục tiêu: Đánh giá biến đổi nồng độ glucose máu ở bệnh nhân đột quy. não (BN $\boxplus Q N)$ giai đoạn cấp tính trước và sau thời gian điều trị tại bệnh viện.

2. ĐỐI TƯợNG VÀ PHƯƠNG PHÁP

2.1. Đối tượng: $98 \mathrm{BN} Đ Q N$ giai đoạn cấp tính điều trị nội trú tại Bệnh viện Trưng 
Vương thành phố Hồ Chí Minh thuộc đối tượng nghiên cứu.

\subsubsection{Tiêu chuẩn lựa chọn}

+ Bệnh nhân được chẩn đoán ĐQN cấp tính.

+ Bao gồm cả nhồi máu não hoặc chảy máu não.

+ Thời gian nhập viện khác nhau kể từ khi xuất hiện triệu chứng của bệnh.

+ Đột quị não được xác định theo tiêu chuẩn của Tổ chức $\mathrm{Y}$ tế Thế giới.

+ Tiêu chuẩn chẩn đoán hình ảnh ĐQN trên chụp cắt lớp vi tính sọ não.

+ Đột quị lần đầu hoặc tái phát.

+ Bệnh nhân được hoặc chưa chẩn đoán bệnh ĐTĐ trước khi đột quị.

+ Đã hoặc chưa được điều trị trước khi nhập viện.

+ Bệnh nhân và/hoặc gia đình đồng ý tham gia nghiên cứu.

\subsubsection{Tiêu chuẩn loại trù̀ đối tựng}

+ Đột quị do phình mạch hoặc dị dạng thông động - tĩnh mạch não.

+ Bệnh nhân u não.

+ Có tiền sử chấn thương sọ não.

+ Đã được truyền dung dịch huyết thanh ngọt trước khi đưa vào nghiên cứu.

+ Đã được sử dụng các thuốc điều trị ĐTĐ cả thuốc uống hoặc tiêm.

+ Tử vong trong vòng 24 giờ kể từ khi nhập viện.

+ Không thu thập đủ các chỉ số theo yêu cầu của nghiên cứu nhất là glucose máu tĩnh mạch, $\mathrm{HbA} 1 \mathrm{c}$.

\subsection{Phương pháp}

Thiết kế nghiên cứu: Tiến cứu, theo dõi dọc trong thời gian bệnh nhân điều trị tại bệnh viện.

\subsubsection{Nội dung nghiên cứu}

+ Khai thác bệnh sử.

+ Khám và theo dõi biểu hiện lâm sàng, trong thời gian điều trị tại bệnh viện.

+ Thực hiện các xét nghiệm chẩn đoán bệnh trong đó có chụp cắt lớp vi tính bao gồm CT hoặc MRI.

+ Tiến hành điều trị $\mathrm{BN}$ dựa vào thể bệnh, mức độ và biểu hiện của $\mathrm{BN}$, mang tính cá thể hóa. Nếu tại thời điểm nhập viện dù trước đó đã chẩn đoán có hay không có ĐTĐ khi glucose $>7,8 \mathrm{mmol} / 1$ sẽ được sử dụng insulin liều lượng tương ứng.

+ Xét nghiệm glucose máu trước và sau thời gian điều trị hoặc tại thời điểm tử vong ở bệnh viện.

2.2.2. Tiêu chuẩn chẩn đoán, phân loại sử dụng trong nghiên cúu.

+ Chẩn đoán ĐQN và thể đột quỵ theo tiêu chuẩn của tổ chức $\mathrm{Y}$ tế Thế giới.

+ Đánh giá rối loạn ý thức theo thang điểm Glassgow.

Bảng 2.1. Tình trạng glucose máu ở bệnh nhân đột quỵ não cấp [80]

\begin{tabular}{|l|c|c|}
\hline \multicolumn{1}{|c|}{ Biểu hiện } & $\begin{array}{c}\text { Glucose máu lúc } \\
\text { nhập viện }\end{array}$ & $\begin{array}{c}\text { HbA1c lúc } \\
\text { nhập viện }\end{array}$ \\
\hline Tăng glucose máu phản ứng & Tăng & Bình thường \\
\hline $\begin{array}{l}\text { Rối loạn dung nạp glucose/ĐTĐ kết hợp với tăng } \\
\text { glucose máu phản ứng }\end{array}$ & Tăng & Tăng \\
\hline $\begin{array}{l}\text { Rối loạn dung nạp glucose/ĐTĐ không kèm theo } \\
\text { tăng glucose máu phản ứng }\end{array}$ & Bình thường & Tăng \\
\hline Không có tăng glucose máu phản ứng & Bình thường & Bình thường \\
\hline
\end{tabular}

Xác định tăng glucose máu ngẫu nhiên lúc nhập viện $>6,0$ mmol/1, HbAlc $\geq 5,7 \%$.

2.2.3. Xủ lý số liệu và đạo đức y học trong nghiên cứu.

+ Xử lý số liệu bẳng phần mềm SPSS 16.0 với việc xác định và so sánh giá trị trung bình, tỷ lệ \%.

+ Nghiên cứu không vi phạm đạo đức y học, không ảnh hưởng đến quá trình điều trị. 


\section{KẾT QUẢ NGHIÊN CÚU}

Bảng 3.1. Tỷ lệ BN tại thời điểm kết thúc nghiên cứu

\begin{tabular}{|l|c|c|}
\hline \multicolumn{1}{|c|}{ Biểu hiện } & Số lượng (n) & Tỷ lệ (\%) \\
\hline Không tử vong & 80 & 81,6 \\
\hline Tử vong & 18 & 18,4 \\
\hline
\end{tabular}

Tỷ lệ tử vong của BN trong thời gian điều trị tại bệnh viện thấp hơn so với không tử vong.

Bảng 3.2. So sánh nồng độ glucose máu khi nhập viện so với khi xuất viện hoặc tử vong $(\mathrm{n}=98)$

\begin{tabular}{|l|c|c|}
\hline \multicolumn{1}{|c|}{ Thời điểm } & Glucose máu (mmol/l) & p \\
\hline Khi nhập viện & $10,52 \pm 5,75$ & \multirow{2}{*}{$\mathrm{p}=0,0001$} \\
\hline Khi xuất viện hoặc tử vong & $7,29 \pm 3,52$ & \\
\hline
\end{tabular}

Nồng độ glucose máu trung bình khi xuất viện hoặc tử vong giảm có ý nghĩa so với khi nhập viện.

Bảng 3.3. So sánh GTTB glucose khi nhập viện và khi xuất viện hoặc tử vong theo các tình trạng đánh giá ban đầu.

\begin{tabular}{|l|c|c|c|}
\hline \multicolumn{1}{|c|}{ Biểu hiện } & $\begin{array}{c}\text { Glucose khi } \\
\text { nhập viện } \\
\text { (mmol/l) }\end{array}$ & $\begin{array}{c}\text { Glucose khi xuất } \\
\text { viện hoặc tữ } \\
\text { vong (mmol/l) }\end{array}$ & p \\
\hline Tăng glucose máu phản ứng (n= 5) & $4,76 \pm 0,44$ & $4,44 \pm 0,74$ & $>0,05$ \\
\hline $\begin{array}{l}\text { RLDNG/ĐTĐ kết hợp tăng glucose máu } \\
\text { phản ứng (n=15) }\end{array}$ & $8,19 \pm 1,75$ & $6,46 \pm 2,98$ & $<0,05$ \\
\hline $\begin{array}{l}\text { RLDNG/ĐTĐ kết hợp tăng glucose máu } \\
\text { phản ứng không kèm theo tăng glucose } \\
\text { máu phản ứng (n=10) }\end{array}$ & $4,94 \pm 1,1$ & $5,43 \pm 1,6$ & $>0,05$ \\
\hline $\begin{array}{l}\text { Không có tăng glucose máu phản ứng } \\
\text { (n=68) }\end{array}$ & $12,25 \pm 5,97$ & $7,95 \pm 3,74$ & $<0,05$ \\
\hline Tống cộng (n=98) & $10,52 \pm 5,75$ & $7,29 \pm 3,52$ & $<0,001$ \\
\hline
\end{tabular}

+ Nồng độ glucose máu ở đối tượng rối loạn dung nạp glucose/ĐTĐ kết hợp tăng glucose máu phản ứng và tình trạng glucose máu bình thường tại thời điểm nhập viện đều giảm có ý nghĩa khi xuất viện hoặc tử vong.

+ Nồng độ glucose máu ở đối tượng tăng glucose máu phản ứng và rối loạn dung nạp glucose /ĐTĐ không kèm theo tăng glucose máu phản ứng tại thời điểm nhập viện khác biệt không có ý nghĩa so với khi xuất viện khi tử vong.

Bảng 3.4. So sánh GTTB glucose khi nhập viện với khi xuất viện hoặc tử vong ở bệnh nhân ĐTĐ và không ĐTĐ.

\begin{tabular}{|l|c|c|c|}
\hline \multicolumn{1}{|c|}{ Đối tượng } & Thời điểm & Glucose $(\mathbf{m m o l} / \mathbf{l})$ & p \\
\hline \multirow{2}{*}{ Không ĐTĐ $(\mathrm{n}=7)$} & Khi vào viện & $8,71 \pm 3,18$ & \multirow{2}{*}{$<0,05$} \\
\cline { 2 - 3 } & Khi xuất viện & $5,60 \pm 1,09$ & \multirow{2}{*}{ ĐTĐ $(\mathrm{n}=91)$} \\
\cline { 2 - 3 } & Khi vào viện & $10,64 \pm 5,89$ & \\
\cline { 2 - 3 } & Khi xuất viện & $7,41 \pm 3,61$ & \\
\hline
\end{tabular}

Nồng độ glucose máu khi xuất viện hoặc tử vong đều giảm hơn có ý nghĩa khi nhập viện. 
Bảng 3.5. So sánh GTTB glucose, $H b A 1 c$ giữa bệnh nhân xuất viện và tử vong

\begin{tabular}{|c|c|c|c|}
\hline Tình trạng & Đối tượng & Glucose (mmol/l) & $\mathbf{p}$ \\
\hline \multirow{2}{*}{ Glucose khi nhập viện } & Tử vong $(\mathrm{n}=18)$ & $12,37 \pm 6,04$ & \multirow{2}{*}{$>0,05$} \\
\hline & Không tử vong $(n=80)$ & $10,08 \pm 5,63$ & \\
\hline \multirow{2}{*}{$\begin{array}{l}\text { Glucose khi xuất viện hoặc tử } \\
\text { vong }\end{array}$} & Tử vong $(\mathrm{n}=18)$ & $8,93 \pm 5,56$ & \multirow{2}{*}{$<0,05$} \\
\hline & Không tử vong ( $\mathrm{n}=80)$ & $6,92 \pm 2,98$ & \\
\hline \multirow{2}{*}{ HbA1c khi nhập viện } & Tử vong $(\mathrm{n}=18)$ & $7,53 \pm 2,48$ & \multirow{2}{*}{$>0,05$} \\
\hline & Không tử vong ( $\mathrm{n}=80)$ & $7,25 \pm 2,1$ & \\
\hline
\end{tabular}

+ Nồng độ glucose máu ở bệnh nhân tử vong tại thời điểm kết thúc nghiên cứu cao hơn so với bệnh nhân không tử vong.

+ Nồng độ glucose, HbAlc ở bệnh nhân tử vong tại thời điểm kết thúc nghiên cứu khác biệt không có ý nghĩa so với bệnh nhân không tử vong.

Bảng 3.6. So sánh tỷ lệ $\mathrm{BN}$ dựa vào mức glucose máu giữa nhóm tử vong và nhóm xuất viện

\begin{tabular}{|c|c|c|c|c|c|}
\hline \multirow{2}{*}{ Glucose máu (mmol/l) } & \multicolumn{2}{|c|}{ Tử vong } & \multicolumn{2}{|c|}{ Xuất viện } & \multirow{2}{*}{$\mathbf{p}$} \\
\hline & $\mathbf{n}$ & $\%$ & $\mathbf{n}$ & $\%$ & \\
\hline$<5,6(\mathrm{n}=36)$ & 5 & 27,8 & 31 & 36,7 & \multirow{4}{*}{$>0,0$} \\
\hline $5,6-6,0(n=6)$ & 0 & 0 & 6 & 6,1 & \\
\hline $6,1-7,0(n=19)$ & 3 & 16,7 & 16 & 20,0 & \\
\hline$>7,0(n=37)$ & 10 & 55,6 & 27 & 33,8 & \\
\hline Tổng cộng $(n=98)$ & 18 & 100 & 80 & 100 & \\
\hline
\end{tabular}

Tỷ lệ $\mathrm{BN}$ dựa vào các mức glucose ở đối tượng tử vong và xuất viện khác biệt không có ý nghĩa thống kê.

Bảng 3.7. So sánh mức glucose máu giữa $\mathrm{BN} Đ T Ð$ và không ĐTĐ tại thời điểm kết thúc nghiên cứu.

\begin{tabular}{|l|c|c|c|c|c|}
\hline \multirow{2}{*}{ Biểu hiện } & \multicolumn{2}{|c|}{ Không ĐTÐ } & \multicolumn{2}{c|}{ ĐTÐ } & \multirow{2}{*}{ p } \\
\cline { 2 - 5 } & $\mathbf{n}$ & $\mathbf{\%}$ & $\mathbf{n}$ & $\mathbf{\%}$ & \\
\hline Glucose $<7 \mathrm{mmol} / \mathrm{l}(\mathrm{n}=61)$ & 6 & 9,8 & 55 & 90,2 & \multirow{2}{*}{$>0,05$} \\
\hline Glucose $\geq 7 \mathrm{mmol} / \mathrm{l}(\mathrm{n}=37)$ & 1 & 2,7 & 36 & 97,3 & \\
\hline Tổng cộng $(\mathrm{n}=98)$ & 7 & 7,1 & 9 & 92,9 & \\
\hline
\end{tabular}

Mức glucose máu tại thời điểm kết thúc nghiên cứu liên quan không có ý nghĩa với đái tháo đường.

\section{BÀN LUẦN}

Với thời gian nằm điều trị tại bệnh viện ngắn nhất là 2 ngày, dài nhất là 20 ngày đã có18,4\% trường hợp tử vong. Đây có thể cũng là tỷ lệ tử vong không cao do ngày nay có nhiều biện pháp điều trị tích cực, tiến bộ, nhiều loại thuốc tốt cùng các biện pháp theo dõi, chăm sóc chuẩn mực. Trong số $\mathrm{BN}$ xuất viện hoặc nói đúng hơn là không tử vong thì cũng có một kết quả khá khả quan với $71,25 \%$ trường hợp được đánh giá là hồiphục tốt; $28,75 \%$ trường hợp tại thời điểm xuất viện còn biểu hiện liệt, yếu chi ở các mức độ khác nhau. Như vậy có thể nhận định kết quả điều trị $\mathrm{BN}$ đột quỵ não cấp trong đề tài này là tương đối tốt, chứng tỏ các biện pháp áp 
dụng điều trị là chuẩn mực cùng sự chăm sóc điều dưỡng tốt. Mặc dù tỷ lệ BN đột quỵ não có mắc đái tháo đường chiếm tỷ lệ rất cao nên số trường hợp đối tượng được sử dụng insulin cũng chiếm tỷ lệ cao, lên đến $77,6 \%$ trường hợp. Tại cơ sở nghiên cứu các đồng nghiệp đã áp dụng khuyến cáo sử dụng insulin khi $\mathrm{BN}$ đột quỵ não có nồng độ glucose máu lúc nhập viện $>7,8 \mathrm{mmol} / 1$ bất kể trước đó có hay không có đái tháo đường. Có thể do tác dụng của nhiều biện pháp phối hợp cũngnhư phản ứng thích nghi, bù trừ tự nhiên đối với tăng glucose máu phản ứng nên tính chung sau thời gian điều trị kể cả số $\mathrm{BN}$ tử vong thì nồng đô glucose máu trung bình giảm đáng kể, có ý nghĩa thống kê.

Có một khuyến cáo được đưa ra và cũng giúp cho việc thực hiện dễ dàng là ở $\mathrm{BN}$ đột quỵ não dù trước đó có hay không có đái tháo đường thì cứ khi glucose máu tăng > $7,8 \mathrm{mmol} / 1$ đều có chỉ định điều trị bằng sử dụng insulin [1]. Có tác giả cho rằng điểm cắt glucose máu gây tử vong ở BN đột quỵ não không có đái tháo đường là $>113,5 \mathrm{mg} / \mathrm{dl}$, trong khi đó nếu ở $\mathrm{BN}$ đái tháo đường thì ngưỡng lại cao hơn $>210,5 \mathrm{mg} / \mathrm{dl}$. Tác giả giải thích mặc dù đều là đột quỵ não, đều có tăng glucose máu như nhau song ở BN đái tháo đường đã có phản ứng thích nghi, bù trừ với nồng độ glucose máu cao hơn do đó điểm cắt giới hạn của glucose máu gây tử vong ở đối tượng này cũng cao hơn [2]. Có tác giả lại nêu ra mức glucose máu đạt mục tiêu ở $\mathrm{BN}$ đột quỵ não nói chung là $5,5-11 \mathrm{mmol} / 1$ [3].

Đặc biệt theo khuyến cáo của Hội Đái tháo đường Hoa Kỳ 2011 thì $\mathrm{BN}$ đột quỵ não cần kiểm soát glucose máu trong khoảng 140$180 \mathrm{mg} / \mathrm{dl}$ nếu đó là $\mathrm{BN}$ đã được chẩn đoán đái tháo đường trước khi đột quy, còn nếu không có đái tháo đường song lại biểu hiện tăng glucose máu phản ứng thì mục tiêu kiểm soát cần được hạ xuống mức thấp hơn, tương ứng 80-140mg/dl [4].

Nếu tính riêng $\mathrm{BN}$ đái tháo đường và không đái tháo đường trước thời điểm nghiên cứu nhận thấy nồng độ glucose máu khi kết thúc nghiên cứu đều giảm có ý nghĩa thống kê ở cả hai phân nhóm.
Kết quả trên đây là sự phối hợp của nhiều biện pháp bao gồm điều trị bệnh chính là đột quỵ não, tiết chế ăn uống, sử dụng thuốc chống tăng glucose máu bằng insulin cùng với phản ứng thích nghi, tự điều chỉnh của co thể đã làm cho nồng độ glucose máu giảm có ý nghĩa.

Một kết quả cũng được cho là có sự phù hợp đó là liên quan glucose, $\mathrm{HbA1c}$ ở $\mathrm{BN}$ tử vong và không tử vong. Theo đó tại thời điểm nhập viên mặc dù nồng độ glucose ở đối tượng tử vong trong quá trình theo dõi có tăng cao hơn so với $\mathrm{BN}$ không tử vong, tuy vậy sự khác biệt không có ý nghĩa thống kê. Qua đó cho thấy tại thời điểm nhập viện thì nồng độ glucose là tương đương nhau. Tuy vậy khi so sánh nồng độ glucose máu trung bình khi xuất viện hoặc tử vong giữa 2 phân nhóm tử vong và không tử vong lại nhận thấy sự khác biệt có ý nghĩa thống kê. Theo đó nồng độ glucose máu ở những trường hợp tử vong cao hơn có ý nghĩa so với những đối tượng không tử vong. Kết quả trên đây cũng phù hợp với những nhận xét đánh giá tiên lượng kém khi tăng glucose máu của nhiều tác giả. Tăng glucose máu là yếu tố tiên lượng tử vong xấu và khả năng hồi phục thần kinh của $\mathrm{BN}$ đột quỵ não. Tác giả cho thấy khi nồng độ glucose $>8,0 \mathrm{mmol} / 1$ là yếu tố tiên lượng xấu tương quan nghịch với mức độ nặng của bệnh [5]. Trong đó đánh giá tại thời điểm nhập viện giữa hai phân nhóm tử vong và không tử vong nhận thấy giá trị trung bình của $\mathrm{HbA}$ c c khác biệt không có ý nghĩa thống kê.

Kết quả trên cũng cho thấy tại thời điểm nhập viên cả nồng độ glucose và $\mathrm{HbA} 1 \mathrm{c}$ giữa 2 phân nhóm tử vong và không tử vong là tương đương nhau. Sự khác biệt chỉ nhận thấy tại thời điểm xuất viện hoặc tử vong chỉ riêng đối với glucose máu.

\section{KẾT LUẬN \\ Biến đổi nồng độ glucose máu sau thời gian điều trị tại bệnh viện. \\ + Nồng độ glucose máu giảm có ý nghĩa. \\ + Đối tượng có rối loạn dung nạp glucose/đái tháo đường có tăng glucose máu phản ứng và không có tăng glucose máu phản}


ứng đơn thuần tại thời điểm nhập viện có nồng độ glucose máu giảm.

+ Giảm nồng độ glucose sau thời gian điều trị tại bệnh viện (kể cả bệnh nhân tử vong) nhận thấy ở cả bệnh nhân đái tháo đường và không đái tháo đường trước khi đột quỵ não.

+ Nồng độ glucose máu ở đối tượng tại thời điểm tử vong cao hơn có ý nghĩa so với đối tượng không tử vong.

+ Tỷ lệ biến đổi các mức glucose máu liên quan không có ý nghĩa giữa bệnh nhân tử vong và không tử vong.

\section{TÀI LIỆU THAM KHẢO}

1. Godoy DA, Soler C, Videtta W, et al. (2012). "Hyperglycemia in nondiabetic patients during the acute phase of stroke”. Arquivos de Neuro - Psiquiatria, 70(2), doi.10.1590.

2. Snarska K, Hanna B, et al. (2017). "Hyperglycemia and diabetes have different impacts on outcome of ischemic and hemorrhagic stroke". Atch Med Sci, 13(1), pp.100-108.

3. Nadya K, Shmuel L, Hilla K (2001). "The role of hyperglycemia in acute stroke”. Arch Neurol, 58(8), pp.12091212.

4. Baker L, Juneja R, Bruno A (2011). "Management of hyperglycemia in acute ischemic stroke”. Curr Treat Options Neurol, 13(6), pp.616-628.

5. Mazighi M, Amarenco P (2001). "Hyperglycemia: a predictor of poor prognosis in acute stroke". Diabetes Metab, 27(6), pp.718-720. 